\title{
Scale-up in the synthesis of nanoparticles for encapsulation of agroindustrial active principles
}

\section{Escalonamento na síntese de nanopartículas para encapsulamento de princípios ativos agroindustriais}

\author{
Dirliane Santos Duarte ${ }^{1}$, José Augusto de Almeida Nascimento ${ }^{2}$ (iD, Douglas de Britto ${ }^{3 *}$ (iD
}

\author{
'Universidade Federal do Vale do São Francisco/UNIVASF, Instituto de Pesquisa em Ciência dos Materiais, Juazeiro, BA, Brasil \\ ¿Universidade Federal de Pernambuco/UFPE, Ciências de Materiais/PGMTR, Recife, PE, Brasil \\ ${ }^{3}$ Empresa Brasileira de Pesquisa Agropecuária/Embrapa, Embrapa Semiárido, Petrolina, PE, Brasil \\ ${ }^{*}$ Corresponding author: douglas.britto@embrapa.br \\ Received in October 7, 2019 and approved in December 19, 2019
}

\begin{abstract}
Given the potentiality of nanoparticles (NP) to load substances as active principle of drugs, cosmetics and food, there is interest in increasing its production. Particularly in the agroindustrial area, the byproducts are source of functional compounds that must be stabilized by encapsulation, for example, to allow its application. Considering the amount of generated byproducts, it is necessary to understand the encapsulation synthesis in a high scale dimension. In this way, the active compounds vitamin C (from the byproduct of the acerola processing) and polyphenols (from the byproduct of grape processing) were nanoencapsulated into chitosan NP at three reactional volumes: $0.1 ; 1.0$ and $10.0 \mathrm{dm}^{3}$. The NP were characterized for yield, particle size, morphology, encapsulation efficiency and release profile. In general, the increase in scale did not influence these parameters. It is found a close similarity for NP size value between the 0.1 and $10.0 \mathrm{dm}^{3}$ reactional volumes. For example, for the blank control, the size was $155 \pm 6$ and $227 \pm 118 \mathrm{~nm}$ respectively for 0.1 and $10.0 \mathrm{dm}^{3}$ reactional volumes. Similarly for the encapsulated acerola byproduct extract ( $373 \pm 44$ and $400 \pm 83 \mathrm{~nm}$ ) and ascorbic acid ( $279 \pm 29$ and $217 \pm 29 \mathrm{~nm}$ ). For the encapsulated skin grape extract, the size decreased sharply from 1040 to $308 \mathrm{~nm}$. The yield per volume ratio was about $1.3 \mathrm{mg} \mathrm{cm}^{-3}$. Additional analysis for NP with encapsulated skin grape extract, by Scanning Electronic Microscopy, showed uniformly distributed spherical structures and the release profile was similar for all reactional volumes. Thus, the system is suitable for scale-up for NP production.
\end{abstract}

Index terms: Vitamin C; polyphenols; byproduct; chitosan.

\begin{abstract}
RESUMO
Dada a potencialidade das nanopartículas (NP) de serem empregadas como vetores para administração de drogas, cosméticos e alimentos, tem-se procurado aumentar a sua produção. Particularmente no setor agroindustrial, os subprodutos são fontes de compostos ativos que precisam ser estabilizados para garantir sua aplicação. No entanto, dado o volume de subproduto gerado, é preciso estudar o encapsulamento em escalas maiores. Assim, visando determinar a influência do escalonamento nas propriedades da NP, a vitamina C (extraída do resíduo do processamento de acerola) e polifenóis (obtido do resíduo do processamento de uva) foram nanoencapsulados em NP de quitosana a partir de três volumes reacionais diferentes: 0,1; 1,0 e 10,0 dm³. As NP foram caracterizadas em relação ao rendimento, tamanho de partícula, morfologia e perfil de liberação. De forma geral, o aumento de escala não influenciou os parâmetros estudados. Assim, os valores de tamanho das NP entre os volumes reacionais de 0,1 e $10,0 \mathrm{dm}^{3}$ foram muito similares. Por exemplo, para o controle (não encapsulado), o tamanho foi $155 \pm 6$ e $227 \pm 118 \mathrm{~nm}$, respectivamente, para os volumes reacionais de 0,1 e $10,0 \mathrm{dm}^{3}$. O mesmo padrão foi observado para o extrato do subproduto de acerola encapsulado ( $373 \pm 44$ e $400 \pm 83 \mathrm{~nm}$ ) e o ácido ascórbico ( $279 \pm 29$ e $217 \pm 29 \mathrm{~nm}$ ). Para o extrato da casca de uva encapsulado, houve um decréscimo de tamanho, variando de 1040 a $308 \mathrm{~nm}$. A razão rendimento por volume ficou em torno de 1,3 mg $\mathrm{cm}^{-3}$. Análises adicionais para NP com extrato da casca de uva encapsulado, por Microscopia Eletrônica de Varredura, mostrou estruturas esféricas uniformemente distribuídas e o perfil de liberação foi independente do volume reacional. Desta forma, o sistema é adequado para o escalonamento.
\end{abstract}

Termos para indexação: Vitamina C; polifenóis; subprodutos; quitosana.

\section{INTRODUCTION}

The nanoencapsulation is a useful procedure to apply controlled release of active compounds with potential application in the pharmacological (Mora-Huertas; Fessi;
Elaissari, 2010), food (Fathi; Martín; McClements, 2014) and agricultural (Badang; Chakraborty, 2019) areas. Several matrices can be used to achieve the encapsulation and to deliver the active substance. Among the matrices, those based on biodegradable material is attractive due 
to apply "Generally Recognized As Safe" (GRAS) materials (Kumari; Yadav; Yadav, 2010). This designation is fundamental mainly for food and pharmaceutical applications (Santos et al., 2016). Chitosan, as an example of such material, is a special polysaccharide that has been widely used to encapsulate and deliver several classes of active compounds such as vitamins (Britto et al., 2014; Britto et al., 2012) and essential oil (Feyzioglu; Tornuk, 2016). Regarding the methods, the ionic gelation is largely studied due to its easiness and mild condition of synthesis (Gan et al., 2005). This procedure is useful for polysaccharide polyelectrolyte such as chitosan that allows interaction with charged and polar species to form stable nanohydrogel. In the case of chitosan, that is a cationic polyelectrolyte, the most used ionic gelation inductor is the sodium tripolyphosphate (TPP), with five negative charged groups (Britto et al., 2014; Britto et al., 2012).

However, many factors can influence the chitosanTPP system in the encapsulation of actives compounds. The chitosan concentration, the ratio chitosan to TPP, $\mathrm{pH}$, kind of acid used to solubilize the chitosan and the solubility of the encapsulated compound play important role in the nanoparticle structure, mainly in its size (Gan et al., 2005) and load capacity/efficiency (Britto et al., 2012; Gan; Wang, 2007). In an attempt to better understand the attribution of such parameters, studies have been conducted to evaluate the influence of the chitosan molecular weight, the ratio of crosslinking agent TPP and the $\mathrm{pH}$ on the property of synthetized NP (Gan et al., 2005). Concerning the NP sizes, it increases steadily with chitosan concentration, equally for low, medium or high molecular weight chitosan. Smallsized NP can be achieved by reacting a low concentration of low or medium molecular weight chitosan. Moreover, by increasing the ratio of chitosan to TPP, the NP size also increases. Finally, low pH favored small-sized NP (Gan et al., 2005; Gokce et al., 2014).

Several efforts have been driven to get the better condition for encapsulation by chitosan-TPP ionic gelation, e.g., through factorial design (Kiilll et al., 2017) or by systematic statistical Design of Experiments (Sreekumar et al., 2018). However, the large-scale production of NP based on TPP has not been explored. While, for other NP systems, such studies were led, for example, for silver-chitosan NP (Wongpreecha et al., 2018) and chitosan nanofibers (Wang et al., 2016). In this way, it is necessary to study such synthesis in large scale, aiming its potential application in the industrial segment. Regarding this, the vitamins are important active compounds to be encapsulated as an ingredient in premixes and feed for fish diets, mainly that hydrosoluble ones (Britto et al., 2016). Other important substances are the phenolic compounds as an active antifungal ingredient in edible coatings to extend the shelflife of perishable fruits and vegetables (Friedman, 2014).

Active substances such as vitamin and phenolic compound are found in agroindustrial byproduct (Valduga et al., 2008). Thus, it is important to evaluate the possibility of direct nanoencapsualtion of such substance from the aqueous extract. This can be carried out, for example, from acerola byproduct, once a previous study showed that in the processed residue still has a significant amount of residual vitamin C (Nascimento et al., 2019). Likewise, for winery byproducts, many phenolic compounds remain in the residue (Melo et al., 2015).

In this way, aiming the synthesis of such NP in a scale compatible with the generated volume of byproducts, some NP characteristics via ionic gelation with TPP were investigated in different scale of production. For this, aqueous extract from the byproduct of acerola juice production (rich in vitamin C) and aqueous/ethanol extract from the byproduct of wine industries (rich in polyphenols) were used as models.

\section{MATERIAL AND METHODS}

\section{Material}

Sodium tripolyphosphate (TPP) and medium molecular weight chitosan (Chi), $80 \%$ deacetylated, were purchased from Aldrich Chemical Company Inc. (USA) and used as supplied. Others chemical as acetic acid (HAc) $\left(\right.$ Vetec $\left.^{\circledR}, 99.7 \%\right)$; metaphosphoric acid P.A. $\left(\right.$ Vetec $\left.^{\circledR}\right)$; hydrochloric acid $\left(37 \% \mathrm{HCl}\right.$, Alphatec $\left.{ }^{\circledR}\right)$; oxalic acid dihydrate P.A. $\left(\right.$ Vetec $\left.^{\circledR}, 99.5-102.5 \%\right)$, L-(+)-ascorbic acid P.A. (AA) $\left(\right.$ Vetec $^{\circledR}$ ) and ethanol P.A. (Sciavicco ${ }^{\circledR}, 99.5 \%$ ) were used as commercially purchased.

The byproduct from acerola processing (Malpighia emarginata D.C., 'Sertaneja' variety) was supplied by Niagro-Nichirei do Brasil Agrícola Ltda. and the byproduct from winery activity (Vitis Vinifera, 'Egiodolla' variety) was supplied by ViniBrasil, both located in Petrolina, PE, Brazil.

\section{Extraction of vitamin C from acerola byproduct}

The basic methodology for the extraction of vitamin $\mathrm{C}$ from acerola byproduct consisted in weighing $5.0 \mathrm{~g}$ of the residue in a Falcon tube and subjecting it to extraction with $50.0 \mathrm{~cm}^{3}$ chitosan aqueous solution $(3.0 \mathrm{mg} \mathrm{cm}$ ) in HAc $0.5 \%(\mathrm{v} / \mathrm{v})$. After manual stirring for dispersion of the residue, the mixture was centrifuged at $12,857 \mathrm{x} \mathrm{g}$ (centrifuge Eppendorf, model 5804 R, rotor F-34-6-38, 
$10,000 \mathrm{rpm}$ ) for 10 minutes and $8{ }^{\circ} \mathrm{C}$ for separation of the solid residue and obtaining the supernatant rich in vitamin C. This supernatant was then subjected to NP synthesis and encapsulation, as described in following.

\section{Extraction of polyphenols from wine byproduct}

The methodology for extraction of polyphenols was based in a hydro-alcoholic extraction. For this, at first, the seeds were separated from the wine byproduct and $200 \mathrm{~g}$ of grape skin was extracted with water-ethanol, as described in the literature (Moura et al., 2011). After the filtration, rota-evaporation and lyophilization, a dry material was obtained and stored in the dark at $-20{ }^{\circ} \mathrm{C}$ until the utilization.

\section{Synthesis and scale-up of chitosan nanoparticle}

The basic procedure for chitosan NP synthesis via ionic gelation consisted in to react $50.0 \mathrm{~cm}^{3}$ of chitosan solution $\left(3.0 \mathrm{mg} \mathrm{cm}^{-3}\right)$ dissolved in HAc $(0.5 \%, \mathrm{v} / \mathrm{v})$ with $50.0 \mathrm{~cm}^{3}$ TPP solution $\left(1.2 \mathrm{mg} \mathrm{cm}^{-3}\right)$ to get $0.1 \mathrm{dm}^{3}$ final volume (Britto et al., 2014). In this case, the $\mathrm{pH}$ of the reactant solutions of chitosan and TPP was respectively 2.93 and 9.58. After the synthesis, the $\mathrm{pH}$ of the NP suspension was 4.4. The TPP solution was added to the chitosan solution at an approximate speed of $1.0 \mathrm{~cm}^{3} \mathrm{~s}^{-1}$ under magnetic stirring $(\sim 500 \mathrm{rpm})$. This NP suspension was taken as a blank sample and called $\mathrm{NP}_{\text {blk }}$. The same procedure was repeated, accounting, however, for final volumes of $1.0 \mathrm{dm}^{3}$ and $10.0 \mathrm{dm}^{3}$. Some adjustment was necessary to implement such scale-up, mainly for synthesis at $10.0 \mathrm{dm}^{3}$. The first was substituting the magnetic stirring for a mechanical one, maintaining the rotation at $500 \mathrm{rpm}$. It was necessary also to increase the TPP speed addition to near $100.0 \mathrm{~cm}^{3} \mathrm{~s}^{-1}$.

The encapsulation of vitamin $\mathrm{C}$ from the acerola byproduct followed the same procedure, substituting the initial chitosan solution by the supernatant rich in vitamin $\mathrm{C}$. This $\mathrm{NP}$ suspension was denominated $\mathrm{NP}_{\text {ace }}$. For comparison, a control system, containing $30.0 \mathrm{mg}$ AA added to $50.0 \mathrm{~cm}^{3}$ chitosan solution in HAc, was also prepared and encapsulated in the same way. This NP suspension was denominated $\mathrm{NP}_{\mathrm{AA}}$.

The polyphenol extract was encapsulated following the same process, with the previous addition of $80.0 \mathrm{mg}$ of dry extract to the TPP solution. In this case, the TPP concentration was $1.0 \mathrm{mg} \mathrm{cm}^{-3}$. The NP suspension was called $\mathrm{NP}_{\text {gra }}$.

\section{Characterization of nanoparticles suspension}

The NP suspensions were analyzed for particle size and zeta potential by Dynamic Light Scattering (DLS) technique (Malvern Instruments ${ }^{\circledR}$, model ZS Zen 3600). The NP suspension was filled into the disposable cuvette without dilution.

The Encapsulation Efficiency (EE) was determined by UV-visible spectrophotometry (ThermoScientific ${ }^{\circledR}$ spectrophotometer, model MultiSkan GO). First, the NP suspension was centrifuged at 35,392 x g (centrifuge Beckman Coulter, model Avanti J26-XP, rotor JA 25.15, $20,000 \mathrm{rpm}$ ) for 20 minutes at $8{ }^{\circ} \mathrm{C}$ and the supernatant quantified for vitamin $\mathrm{C}$ or phenolic compound. For this, calibrations curves were set with appropriated concentrations of AA in metaphosphoric acid $(1.0 \%$ $\mathrm{w} / \mathrm{v})$ or freeze-dried skin grape extract in ethanol-water solution (1:1). The maximum absorbance in the UVVisible spectrum (200-400 $\mathrm{nm}$ range) was $240 \mathrm{~nm}$ for AA and $278 \mathrm{~nm}$ for grape extract. The resultant calibration curve fit was $\mathrm{y}=0.0131+56.2476 \mathrm{x}\left(\mathrm{R}^{2}=0.9995\right)$ for ascorbic acid and $\mathrm{y}=-0.1878+8.7375 \mathrm{x}\left(\mathrm{R}^{2}=0.9738\right)$ for grape extract. The EE was calculated according to the following equation:

$$
\mathrm{EE}=\frac{(\text { total initial substance })-(\text { non }- \text { encapsulated substance })}{\text { total initial substance }} \times 100
$$

The precipitate resulted from the centrifugation was submitted to lyophilization for yield calculation and expressed as a ratio of recovered mass per reactional volume.

Given the high EE value for NP suspension with encapsulated skin grape extract, it was chosen for morphologic and release profile additional analyses. The morphologic analysis was done by Scanning Electron Microscopy (SEM) (Tescan ${ }^{\circledR}$ equipment, model Vega 3). For this, the samples were previously centrifuged at 35,392 $\mathrm{x} \mathrm{g}$ (centrifuge Beckman Coulter, model Avanti J26-XP, rotor JA $25.15,20,000 \mathrm{rpm}$ ) for 20 minutes at $8{ }^{\circ} \mathrm{C}$ and stabilized in a sucrose solution at $5 \%$ before lyophilization (cryogenic treatment). Following, the dry sample was washed with deionized water under ultrasonic bath several times. After that, the suspension was deposited in a glass sheet and coated with a gold layer.

For the release profile, $10.0 \mathrm{~g}$ of the centrifuged precipitated NP was suspended in $60 \%$ ethanol-phosphate buffer solution under orbital agitation at $120 \mathrm{rpm}$ and $25{ }^{\circ} \mathrm{C}$. At pre-determinate time intervals, aliquots of the suspension were taken, centrifuged and the supernatant quantified by UV-Visible spectroscopy, as described above. The experiment was done in duplicate. The normalization was done by the Origin ${ }^{\circledR}$ Lab SR0 software, v. 8.0725, applying the [0.1] method. 


\section{RESULTS AND DISCUSSION}

\section{Encapsulation efficiency and yield in the scale-up}

The systems did not show significant variations for supernatant concentration, encapsulation efficiency and yield as function of the reactional volume (Table 1) However, for NP suspensions with encapsulated ascorbic acid and acerola extract, there was a slight decrease in EE according to the increase of the reactional volume. On the other hand, for $\mathrm{NP}_{\text {gra }}$ there was no trend in the EE variation. Comparing EE values for $\mathrm{NP}_{\text {ace }}$ and $\mathrm{NP}_{\text {gra }}$, it is seen a great difference, in which the former showed lower EE values.

The variation observed for the parameters SC, $\mathrm{EE}$ and $\mathrm{YR}$ are in agreement with discussed before and is due mainly to the solubility and solvatation of each encapsulated compound in the reactional solvent (Britto et al., 2012). Another important data in the characterization of $\mathrm{NP}$ is its yield expressed in terms of total mass recovered after centrifugation and separation from the supernatant. According to the results, the yield ratio did not show significant variations for any of the reactional volumes (Table 1). These results indicate the stability of the system through the scale-up in the range 0.1 to $10.0 \mathrm{dm}^{3}$.

\section{Nanoparticle size and zeta potential in the scale-up}

The size of NP measured by DLS showed variations in function of the reactional volume and the presence of encapsulated substance (Table 2). For the blank system (without active compound), the NP size had the lowest value, considering the reactional volume of $0.1 \mathrm{dm}^{3}$. For $1.0 \mathrm{dm}^{3}$, it increased but remained the same value for 10.0 $\mathrm{dm}^{3}$. This size distribution is in accordance with reported early (Gan et al., 2005; Britto et al., 2012; Neves et al., 2014). This result attests the feasibility of the methods for scale-up, considering the adaptations for large scale that was made. In the same way, for the NP suspension with encapsulated ascorbic acid, the variation in size was not

Table 1: Values for supernatant concentration (SC, $\mathrm{mg} \mathrm{cm}^{-3}$ ), encapsulation efficiency (EE, \%) and yield ratio $\left(\mathrm{YR}, \mathrm{mg} \mathrm{cm}^{-3}\right)$, as a ratio of recovered mass per reactional volume, for nanoparticles suspensions in the three reactional volumes.

\begin{tabular}{|c|c|c|c|c|c|c|c|c|c|}
\hline \multirow{3}{*}{ Sample } & \multicolumn{9}{|c|}{ Reactional volume } \\
\hline & \multicolumn{3}{|c|}{$0.1 \mathrm{dm}^{3}$} & \multicolumn{3}{|c|}{$1.0 \mathrm{dm}^{3}$} & \multicolumn{3}{|c|}{$10.0 \mathrm{dm}^{3}$} \\
\hline & SC & $\mathrm{EE}$ & YR & SC & $\mathrm{EE}$ & YR & SC & $\mathrm{EE}$ & YR \\
\hline $\mathrm{NP}_{\mathrm{blk}}$ & - & - & 1.36 & - & - & 1.06 & - & - & 1.24 \\
\hline$N P_{\text {ace }}$ & 0.491 & 39.9 & 1.25 & 0.583 & 28.6 & 0.7 & 0.637 & 21.9 & 1.24 \\
\hline $\mathrm{NP}_{\mathrm{AA}}$ & 0.249 & 17.1 & 1.36 & 0.262 & 12.6 & 1.08 & 0.268 & 10.8 & 1.22 \\
\hline $\mathrm{NP}_{\mathrm{gra}}$ & 0.262 & 67.2 & 1.35 & 0.274 & 65.7 & 1.54 & 0.256 & 68.0 & 1.40 \\
\hline
\end{tabular}

$\mathrm{NP}_{\text {blk }}$ : blank nanoparticles suspension (without active compound); $\mathrm{NP}_{\text {ace: }}$ : nanoparticles suspension with encapsulated acerola extract; $\mathrm{NP}_{\mathrm{AA}}$ : nanoparticles suspension with encapsulated ascorbic acid; $\mathrm{NP}_{\text {gra }}$ : nanoparticles suspension with encapsulated grape extract.

Table 2: Values for nanoparticle size $(\mathrm{nm})$ and zeta potential $(\mathrm{ZP}, \mathrm{mV})$ for nanoparticles suspensions in the three reactional volumes.

\begin{tabular}{ccccccr}
\hline \multirow{2}{*}{ Sample } & \multicolumn{7}{c}{ Reactional volume } \\
\cline { 2 - 7 } & \multicolumn{2}{c}{$0.1 \mathrm{dm}^{3}$} & \multicolumn{2}{c}{$1.0 \mathrm{dm}^{3}$} & \multicolumn{2}{c}{$10.0 \mathrm{dm}^{3}$} \\
\cline { 2 - 7 } & \multicolumn{1}{c}{ Size } & \multicolumn{1}{c}{ ZP } & \multicolumn{1}{c}{ Size } & ZP & \multicolumn{1}{c}{ SPe } \\
\hline $\mathrm{NP}_{\text {blk }}$ & $155 \pm 6$ & $27.4 \pm 0.8$ & $850 \pm 85$ & $27.5 \pm 0.5$ & $227 \pm 118$ & $24.3 \pm 0.4$ \\
$\mathrm{NP}_{\text {AA }}$ & $279 \pm 29$ & $26.2 \pm 0.6$ & $480 \pm 39$ & $22.3 \pm 0.7$ & $217 \pm 29$ & $24 \pm 1.1$ \\
$\mathrm{NP}_{\text {gra }}$ & $1040 \pm 149$ & $32 \pm 1.2$ & $739 \pm 40$ & $31.3 \pm 0.9$ & $308 \pm 19$ & $27.1 \pm 0.2$ \\
$\mathrm{NP}_{\text {ace }}$ & $373 \pm 44$ & $22.2 \pm 0.7$ & $1000 \pm 100$ & $25.2 \pm 0.8$ & $400 \pm 83$ & $24.5 \pm 0.9$ \\
\hline
\end{tabular}

$\mathrm{NP}_{\text {blk: }}$ : blank nanoparticles suspension (without active compound); $\mathrm{NP}_{\text {ace }}$ : nanoparticles suspension with encapsulated acerola extract; $\mathrm{NP}_{\mathrm{AA}}$ : nanoparticles suspension with encapsulated ascorbic acid; $\mathrm{NP}_{\mathrm{gra}}$ : nanoparticles suspension with encapsulated skin grape extract. 
significant, mainly for the reactional volumes of $0.1 \mathrm{dm}^{3}$ and $10.0 \mathrm{dm}^{3}$. Generally, comparing the blank control with the encapsulated ones, there is an increase in the NP size. This was observed before and it is related to the increase of crosslinking density among the species (Gan; Wang, 2007; Britto et al., 2012). This find confirms the huge influence caused on the NP architecture by the addition of third species (encapsulated substance) in comparison with the dual system (polymer and crosslinker only) (Britto et al., 2012; Geçer et al., 2010). For skin grape extract, there was a sharp downward trend in size for larger reactional volume. Finally, for acerola extract, the first and last reactional volumes were similar regarding NP size (Nascimento et al., 2019). According to the results, it is found a close similarity for NP size distribution between the first and the last reactional volumes studied. In this way, the ionic gelation process with chitosan and TPP is viable for scale-up.

Regarding the zeta potential value, there was a slight decrease for $\mathrm{NP}_{\mathrm{blk}}$ mainly for the highest reactional volume (Table 2). However, for $\mathrm{NP}_{\mathrm{AA}}, \mathrm{NP}_{\text {gra }}$ and $\mathrm{NP}_{\text {acee }}$, there is no specific trend, except a high overall value for $\mathrm{NP}_{\text {gra }}$, mainly at $0.1 \mathrm{dm}^{3}$ and $1.0 \mathrm{dm}^{3}$, in comparison with $\mathrm{NP}_{\mathrm{blk}}$. The zeta potential gives a measurement of the stability of the system regarding the net surface charge. When chitosan and TPP are mixed in dilute acid solution, they spontaneously form nanocomplexes with an overall positive surface charge (Gan et al., 2005). In this way, depending on the structure of the complex polymerencapsulated substance-TPP, its value can either increase or decrease. The general high values for zeta potential observed for the encapsulated systems confirm the stable character of these nanoparticle suspensions in all the reactional volumes.

\section{Nanoparticles morphology}

The SEM analysis showed regular and spherical $\mathrm{NP}$ distribution for $\mathrm{NP}_{\text {gra }}$ obtained at $0.1 \mathrm{dm}^{3}$ (Figure 1a). However, it is also seen large structure marked as " $\mathrm{A}$ ", resulted from the aggregate formation. On the other hand, for $\mathrm{NP}_{\text {gra }}$ obtained at $1.0 \mathrm{dm}^{3}$, the NP distribution is very irregular (Figure 1b). Selecting randomly 10 structures in Figure 1a and calculating its diameters, it was found an average of $431 \mathrm{~nm}$ (Table 3). This value is inferior that calculated by the DLS technique. The main reason for this is that the SEM technique is related to the dry solid-state in comparison with the hydrodynamical one by the DLS technique.
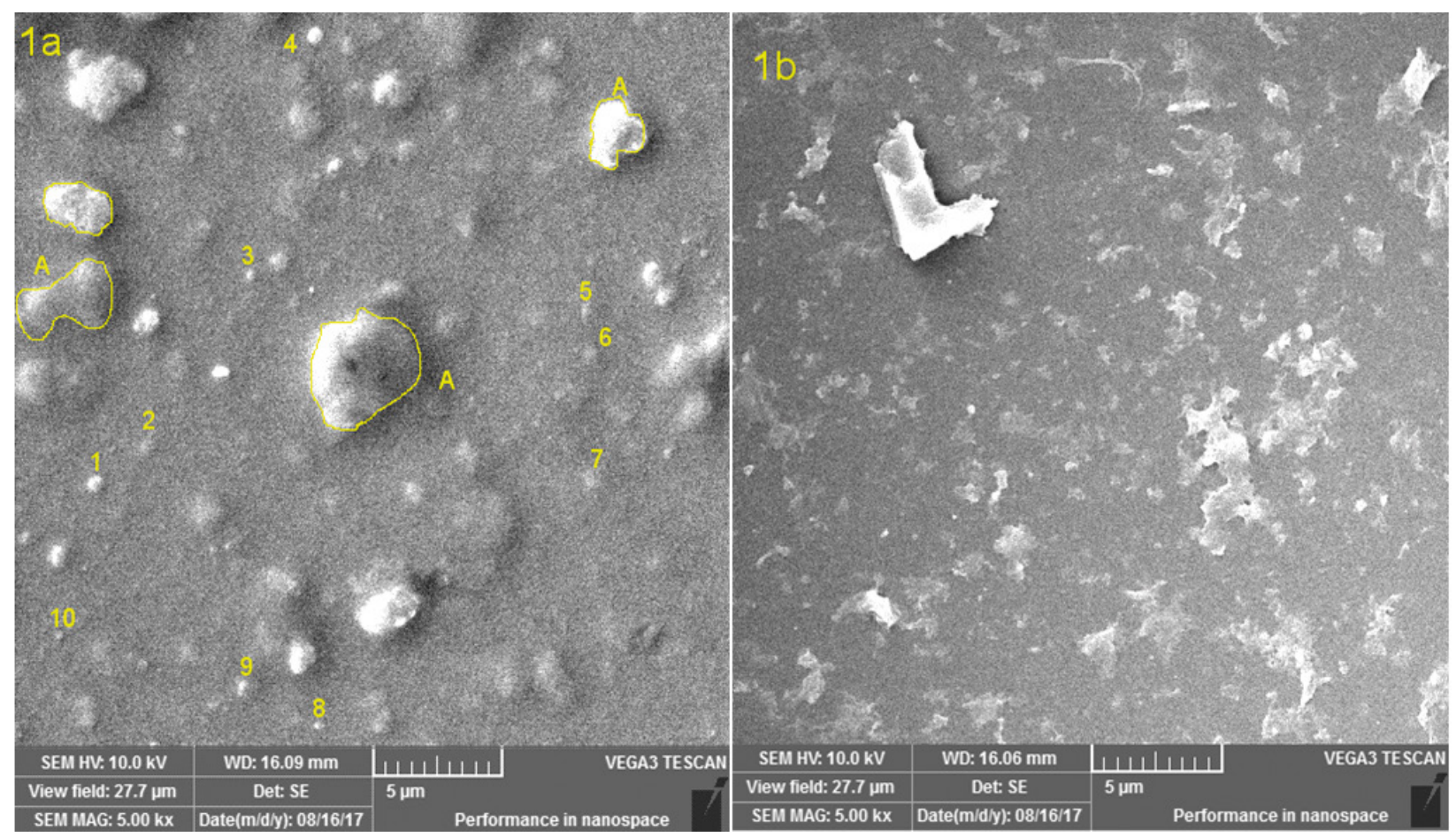

Figure 1: Scanning Electron Microscopy pictures for the nanoparticles suspension with encapsulated skin grape extract deposited on a glass sheet for sample synthetized at a) $0.1 \mathrm{dm}^{3}$ and b) $1.0 \mathrm{dm}^{3}$. 
Table 3: Size distribution for nanoparticles suspension with encapsulated skin grape extract synthetized at $0.1 \mathrm{dm}^{3}$, according to Scanning Electron Microscopy measurement in Figure 1.

\begin{tabular}{cc}
\hline Position & Size $(\mathrm{nm})$ \\
\hline 1 & 570 \\
2 & 584 \\
3 & 270 \\
4 & 584 \\
5 & 348 \\
6 & 411 \\
7 & 570 \\
8 & 380 \\
9 & 348 \\
10 & 247 \\
Average & $431 \pm 127$ \\
\hline
\end{tabular}

The morphological analysis also confirmed the size variation between the reactional volumes of 0.1 and $1.0 \mathrm{dm}^{3}$. Despite the irregularity in the shape distribution (Figure 1b), in general, the size distribution for the sample synthetized at $1.0 \mathrm{dm}^{3}$ is inferior that observed for the sample synthetized at $0.1 \mathrm{dm}^{3}$ (Figure 1a) that is accordance with found in Table 2.

The isolation process by centrifugation and lyophilization generated some "defects", resulting in agglomeration in the isolated hydrogel ("A" structures in Figure 1a). Although, in general, the cryogenic treatment preserves the NP structure (Shahgaldian et al., 2003). However, some physical-chemistry variation in the isolation process, e.g., aggregation after centrifugation, dispersion by ultrasound, can influence the regularity and distribution of the NP.

\section{Release profile}

The release profile for the sample $\mathrm{NP}_{\text {gra }}$ showed differences in the three reactional volumes regarding the absolute concentration (Figure 2a). In a period of 24 hours, the sample $\mathrm{NP}_{\text {gra }}$, synthetized at the lowest reactional volume, exhibited an accumulated final concentration of $0.3 \mathrm{~m} \mathrm{~cm}^{3}$; for $\mathrm{NP}_{\text {gra }}$ synthetized at intermediate volume, the accumulated final concentration was $2.0 \mathrm{mg} \mathrm{cm}^{3}$ and, finally, for that synthetized at the highest volume, the accumulated final concentration was $3.4 \mathrm{mg} \mathrm{cm} 3$. On the other hand, for the normalized concentration (Figure 2b), the release profile was similar in all cases.

The difference found in the accumulated final concentration in function of the reactional volume may be related to the number of centrifugation cycles necessary to isolate the NP. For high reactional volume, it was necessary more centrifugation cycles to precipitate the NP, getting a more concentrated hydrogel. However, the close similarity in the normalized plot (Figure $2 b$ ) indicates the absence of difference in the release profile. The profile is typical of an initial burst release, reaching a plateau of
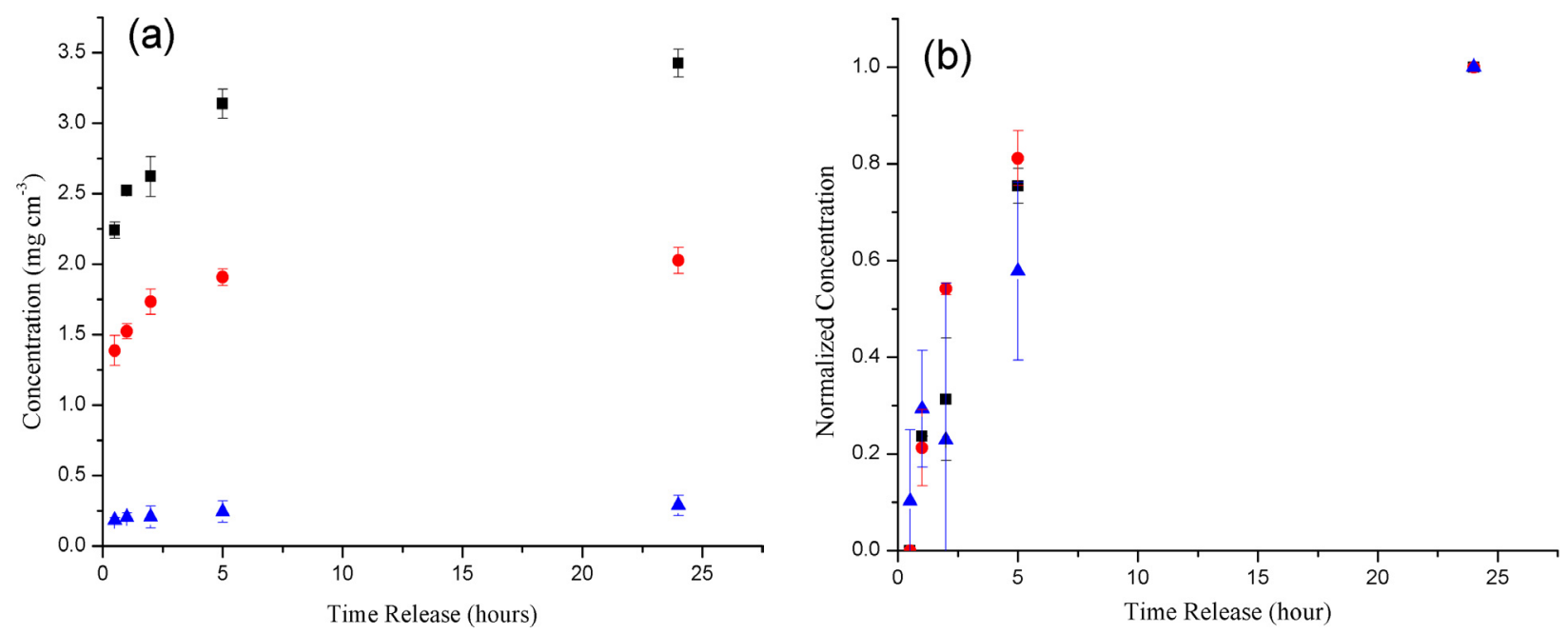

Figure 2: Release profile for the nanoparticles suspension with encapsulated skin grape extract synthetized in the three reactional volumes: $0.1 \mathrm{dm}^{3}(\mathbf{\Lambda}), 1.0 \mathrm{dm}^{3}(\bullet)$ and $10.0 \mathrm{dm}^{3}(\mathbf{\bullet})$ relative to a) absolute concentration and b) normalized concentration. 
constant release after near 5 hours. Such time is strictly dependent on the several factors, e.g., solvent composition, $\mathrm{pH}$, molecular weight of the encapsulated compound, NP characteristics and others (Britto et al., 2012). In a recent study with the polyphenol epigallocatechin gallate encapsulated in chitosan-zein NP, the plateau was reached in different time interval whether the release condition was $50 \%$ or $95 \%$ of ethanol (Liang et al., 2017). On the other hand, for another polyphenol gallic acid encapsulated in poly(lactic-co-glycolic acid) nanoparticles, the plateau was reached at near 10 hours (Alves; Mainardes; Khalil, 2016). Particularly, for the polyphenol extracted from winery byproduct, it is a very complex substance, having many different compounds with specific physical-chemistry properties and, therefore, different release profile.

\section{CONCLUSIONS}

The major characteristic of the nanoparticle, that is its size, showed a close similarity for the lowest and highest reactional volumes. Further, for skin grape extract, the nanoparticle size decreased constantly in function of increasing reactional volume. This attests that the ionic gelation system with chitosan and TPP is suitable for scaling-up the nanoencapsulation of agroindustrial byproduct extract from acerola and grape. However, due to its high dependency on the kind of substance to be encapsulated, the suitability for other kinds of active substance must be studied. All other properties of the system, e.g., yielding, encapsulation efficiency, morphology and release profile showed minimal variation according to the reactional volume, attesting its suitability for scaling-up.

\section{REFERENCES}

ALVES, A. C. S.; MAINARDES, R. M.; KHALIL, N. M. Nanoencapsulation of gallic acid and evaluation of its cytotoxicity and antioxidant activity. Materials Science and Engineering: C, 60:126-134, 2016.

BADANG, M. C. N.; CHAKRABORTY, S. Carbohydrate polymers as controlled release devices for pesticides. Journal of Carbohydrate Chemistry, 38(1):67-85, 2019.

BRITTO, D. et al. N,N,N-trimethyl chitosan nanoparticles as a vitamin carrier system. Food Hydrocolloids, 27(2):487493, 2012.

BRITTO, D. et al. Entrapment characteristics of hydrosoluble vitamins loaded into chitosan and N,N,N-trimethy chitosan nanoparticles. Macromolecular Research, 22(12):12611267, 2014.
BRITTO, D. et al. Analysis of thermal and aqueous suspension stabilities of chitosan based nanoencapsulated vitamins. Química Nova, 39(9):1126-1130, 2016.

FATHI, M.; MARTÍN, Á.; MCCLEMENTS, D. J. Nanoencapsulation of food ingredients using carbohydrate based delivery systems. Trends in Food Science \& Technology, 39(1):1839, 2014.

FEYZIOGLU, G. C.; TORNUK, F. Development of chitosan nanoparticles loaded with summer savory (Satureja hortensis L.) essential oil for antimicrobial and antioxidant delivery applications. LWT - Food Science and Technology, 70:104-110, 2016.

FRIEDMAN, M. Antibacterial, antiviral, and antifungal properties of wines and winery byproducts in relation to their flavonoid content. Journal of Agricultural and Food Chemistry, 62(26):6025-6042, 2014.

GAN, Q.; WANG, T. Chitosan nanoparticle as protein delivery carrier: Systematic examination of fabrication conditions for efficient loading and release. Colloids and Surfaces B: Biointerfaces, 59(1):24-34, 2007.

GAN, Q. et al. Modulation of surface charge, particle size and morphological properties of chitosan-TPP nanoparticles intended for gene delivery. Colloids and Surfaces B, 44(23): 65-73, 2005.

GEÇER, A. et al. Trimethyl chitosan nanoparticles enhances dissolution of the poorly water-soluble drug Candesartan Cilexetil. Macromolecular Research, 18(10):986-991, 2010.

GOKCE, Y. et al. Ultrasonication of chitosan nanoparticle suspension: Influence on particle size. Colloids and Surfaces A: Physicochemical and Engineering Aspects, 462:75-81, 2014.

KIILLL, C. P. et al. Synthesis and factorial design applied to a novel chitosan/sodium polyphosphate nanoparticles via ionotropic gelation as an RGD delivery system. Carbohydrate Polymers, 157:1695-1702, 2017.

KUMARI, A.; YADAV, S. K.; YADAV, S. C. Biodegradable polymeric nanoparticles based drug delivery systems. Colloids and Surfaces B: Biointerfaces, 75(1):1-18, 2010.

LIANG, J. et al. Encapsulation of epigallocatechin gallate in zein/ chitosan nanoparticles for controlled applications in food systems. Food Chemistry, 231:19-24, 2017.

MELO, P. S. et al. Winery by-products: Extraction optimization, phenolic composition and cytotoxic evaluation to act as a new source of scavenging of reactive oxygen species. Food Chemistry, 181:160-169, 2015. 
MORA-HUERTAS, C. E.; FESSI, H.; ELAISSARI, A. Polymer-based nanocapsules for drug delivery. International Journal of Pharmaceutics, 385(1-2):113-142, 2010.

MOURA, R. S. et al. Addition of açaí (Euterpe oleracea) to cigarettes has a protective effect against emphysema in mice. Food and Chemical Toxicology, 49(4):855-863, 2011.

NASCIMENTO, J. A. A. et al. Stability of nanocomposite edible films based on polysaccharides and vitamin C from agroindustrial residue. Materials Research, 22(3): e20190057, 2019.

NEVES, A. L. P. et al. Factorial design as tool in chitosan nanoparticles development by ionic gelation technique. Colloids and Surfaces A: Physicochemical and Engineering Aspects, 445:34-39, 2014.

SANTOS, P. P. et al. Biodegradable polymers as wall materials to the synthesis of bioactive compound nanocapsules. Trends in Food Science \& Technology, 53:23-33, 2016.
SHAHGALDIAN, P. et al. A study of the freeze-drying conditions of calixarene based solid lipid nanoparticles. European Journal of Pharmaceutics and Biopharmaceutics, 55(2):181-184, 2003.

SREEKUMAR, S. et al. Parameters influencing the size of chitosan-TPP nano- and microparticles. Scientific Reports, 8(4695):1-11, 2018.

VALDUGA, E. et al. Extração, secagem por atomização e microencapsulamento de antocianinas do bagaço da uva "Isabel" (Vitis labrusca). Ciência e Agrotecnologia, 32(5):1568-1574, 2008.

WANG, L. et al. Needleless electrospinning for scaled-up production of ultrafine chitosan hybrid nanofibers used for air filtration. RSC Advances, 6(107):105988-105995, 2016.

WONGPREECHA, J. et al. One-pot, large-scale green synthesis of silver nanoparticles-chitosan with enhanced antibacterial activity and low cytotoxicity. Carbohydrate Polymers, 199: 641-648, 2018. 